\title{
Stereopsis in patients of refractive accomodative Esotropia
}

\author{
Abstract \\ Purpose: To find out the factors that is associated with stereopsis in patients with \\ refractive accommodative esotropia.
}

Material and Methods: Patients with refractive accommodative esotropia were checked. Age, sex, cycloplegic refractive error, angle of deviation, stereoacuity and fusional ability were evaluated. Patients were divided into good stereopsis $(40-100 \operatorname{arcsec})$ and poor stereopsis (>100 arcsec group) as well.

Results: Total 30 patients with accommodative esotropia were included in this study. The mean age at presumed age of onset was $2.95 \pm 1.51$ and mean age of the patient at final visit were $6.12 \pm 1.57$.The frequency of male were $56.7 \%(\mathrm{n}=17)$ and female were $43.3 \%(n=13)$. The initial mean cycloplegic refraction was $3.5 \pm 1.35 \mathrm{D}$. The mean initial uncorrected deviation at near fixation was $23.33 \pm 9.57$ and was $20.83 \pm 8.71$ at distant fixation. The mean of angle of deviation after treatment was $2.41 \pm 2.16$ at distant fixation and was $2.14 \pm 1.22$ at near fixation. The mean of fusional ability at final visit was $1.87 \pm 0.93$ at near and $1.90 \pm 0.96$ at distance. The mean stereopsis at final visit was $1.67 \pm 0.47$. The independent-t test shows a significant association of refractive error (P- 0.00) with stereopsis. T-test also shows a signification of angle of deviation after correction for both distant and near (P-value 0.003, 0.006 respectively). The uncorrected angle of deviation for both distant and near had no association ( $\mathrm{p}$ value $0.53,0.083$ respectively). Chi-square test shows a highly significant association of fusional ability for both distant and near ( $\mathrm{p}$-value $0.001,0.001$ respectively) with final stereopsis.

Conclusion: Error of refraction, deviation angle and fusional ability were associated with stereopsis in patients with refractive accommodativeesotropia. The age and gender had no association with stereopsis. The chi- square test shows a significant association of fusional ability with stereopsis. The independent- $t$ test shows a significant association of angle of deviation and refractive error with stereopsis. Good stereopsis can be achieved with hyperopic mean error of less than or equal to $2 \mathrm{D}$.

Keywords: stereopsis, refractive accommodativeesotropia, deviation
Volume 9 Issue $3-2019$

\section{lqra lqbal, Rabia Saeed, Javaria Asif Bajwa, Sadia Falak}

Optometrist, University of Faisalabad, Pakistan

Optometrist, Aziz Fatima Hospital, Pakistan

Optometrist, King Edward Medical University, Pakistan

Assistant Professor, School of Pharmacy, University of Faisalabad, Pakistan

Correspondence: Iqra lqbal, Optometrist, The University of Faisalabad, Madina Teaching Hospital, Faisalabad, Pakistan, Tel 03477799654,Email seventhsky4I@yahoo.com

Received: May 13, 2019| Published: May 17, 2019

\section{Introduction}

Accommodative esotropia is considered as an inward deviation of the eyes that has associations with accommodation reflex activation. It can be ruled out with decrease in inward deviation with use of full spectaclecycloplegic correction and the residual distance and near esodeviation are smaller then 8-10 diopters. Patient with refractive accommodativeesotropiausually have good binocular functions only if the eyes are aligned by correcting hyperopia. ${ }^{1-3}$ It is found that anisometropia, longer duration of esodeviation ${ }^{4}$, and residual esodeviation ${ }^{5-6}$ are associated with poor type of stereopsis. But we still do not know clearly about the factors associated with stereopsis in refractive accommodative esotropia. And the criteria to achieve best and normal binocular sensory functions have yet to establish. This study will investigate the associated factors of stereopsis in refractive accommodative esotropic patients.

\section{Subjects and methods}

The present study included patients of refractive accommodative esotropia seen at Allied Hospital and Madina Teaching Hospital, Faisalabad. Before examination, cycloplegic refraction was done with instillation 1 drop of cyclopentolate $1 \%$ in 3 times in 30 mins.
In addition cycloplegic refraction was repeated at the interval of 6 months to adjust the spectacle correction when needed.

Refractive accommodative esotropia is now defined as a residual esotropia $<10$ degree after full hyperopic correction. Patients with a history of previous strabismus surgery, a congenital or acquired ophthalmic condition, systemic diseases, amblyopia, poor cooperation during stereopsis testing or the alternate prism cover testing or spherical equivalent difference of more than $2 \mathrm{D}$ between the two eyes were not included. The simultaneous prism cover test was performed to find out the angle of deviation. And only the angle of tropia were checked and noted. Patients who had no manifest deviation on simultaneous cover test were designated as fully accommodative esotropes. On the other hand, with residual manifest deviation were designated as having residual esotropes. Measurement of stereopsis was done by using Titmus test. Patient was shown the stereogram at distance of $40 \mathrm{~cm}$ when he was wearing polarizing glasses. Fusion is checked using the worth 4-Dot test at distance as well as near fixation. The results divided into further three groups named, fusion, suppression and diplopia. All the data was entered and analyzed using Statistical Package for Social Science (SPSS Version 20.0). All the data was presented in forms of bar charts. 


\section{Results}

A total of 30 patients with accommodative esotropia were included in this study. The mean age at presumed age of onset was $2.95 \pm 1.51$ and mean age of the patient at final visit were $6.12 \pm 1.57$. The frequency of male were $56.7 \%(\mathrm{n}=17)$ and female were $43.3 \%$ $(n=13)$. The initial mean cycloplegic refraction was $3.5 \pm 1.35$ D. The mean initial uncorrected deviation at near fixation was $23.33 \pm 9.57$ and was $20.83 \pm 8.71$ at distant fixation. The mean of angle of deviation after treatment was $2.41 \pm 2.16$ at distant fixation and was $2.14 \pm 1.22$ at near fixation. The mean of fusional ability at final visit was $1.87 \pm 0.93$ at near and $1.90 \pm 0.96$ at distance. The mean stereopsis at final visit was $1.67 \pm 0.47$ (Table 1).

Table I Characteristics of the accommodative esotropia with general variables

\begin{tabular}{|c|c|c|}
\hline Variables & Values Mean & $\begin{array}{l}\text { Standard Deviation } \\
\text { S.D }\end{array}$ \\
\hline $\begin{array}{l}\text { Age at presumed onset, } \\
\text { years }\end{array}$ & 2.9 & 1.51 \\
\hline Age at final Visit & 6.13 & 1.57 \\
\hline \multicolumn{3}{|l|}{ Gender } \\
\hline \multicolumn{3}{|l|}{ Male } \\
\hline & 1.43 & 0.504 \\
\hline \multicolumn{3}{|l|}{ Female } \\
\hline $\begin{array}{l}\text { Initial Cycloplegicrefractive } \\
\text { Error }\end{array}$ & 3.5 & 1.35 \\
\hline \multicolumn{3}{|l|}{ Initial uncorrected deviation } \\
\hline At distant & 20.83 & 8.71 \\
\hline At near & 23.33 & 9.57 \\
\hline \multicolumn{3}{|l|}{ Deviation after treatment } \\
\hline At Distant & 2.41 & 2.16 \\
\hline At near & 2.14 & 1.22 \\
\hline \multicolumn{3}{|l|}{ Fusional ability at final visit } \\
\hline At distant & 1.9 & 0.96 \\
\hline At near & 1.87 & 0.93 \\
\hline $\begin{array}{l}\text { Orthophoria and residual } \\
\text { esotropia }\end{array}$ & 1.53 & 0.507 \\
\hline Stereopsis at final visit & 1.67 & 0.47 \\
\hline
\end{tabular}

\section{Factors associated with stereopsis}

Out of 30 patients $33.3 \%(n=10)$ had good stereopsis and $66.7 \%$ $(\mathrm{n}=20)$ patients had poor stereopsis.

\section{Mean refractive error}

The initial mean cycloplegic refractive error was $2.00 \pm 0.577$ in good stereopsis group and was $4.27 \pm 0.90$ in poor stereopsis group (P- 0.00) (Table 2).
Table 2 Status of stereopsis with general variable and refractive error

\begin{tabular}{llcl}
\hline \multirow{2}{*}{ Variables } & \multicolumn{2}{c}{ Stereopsis (Means and S.D) } & P-Value \\
\cline { 2 - 3 } & Good & Poor & \\
\hline $\begin{array}{l}\text { Age at presumed } \\
\text { Onset }\end{array}$ & $2.05+1.49$ & $3.4+1.35$ & 0.19 \\
Age at final visit & $5.20+1.03$ & $6.60+1.60$ & 0.18 \\
Gender & $1.40+0.5 \mathrm{I}$ & $1.45+0.5 \mathrm{I}$ & 0.8 \\
$\begin{array}{l}\text { Initial Cycloplegic } \\
\text { Refractive error }\end{array}$ & $2.0+0.57$ & $4.27+0.90$ & 0 \\
\hline
\end{tabular}

\section{Orthophoria and residual esotropia}

Out of 30 refractive accommodative esotropic patients there were $46.7 \%(\mathrm{n}=14)$ patients were orthophoric and $53.3 \%(\mathrm{n}=16)$ patients were with residual esotropia (Figure 1).

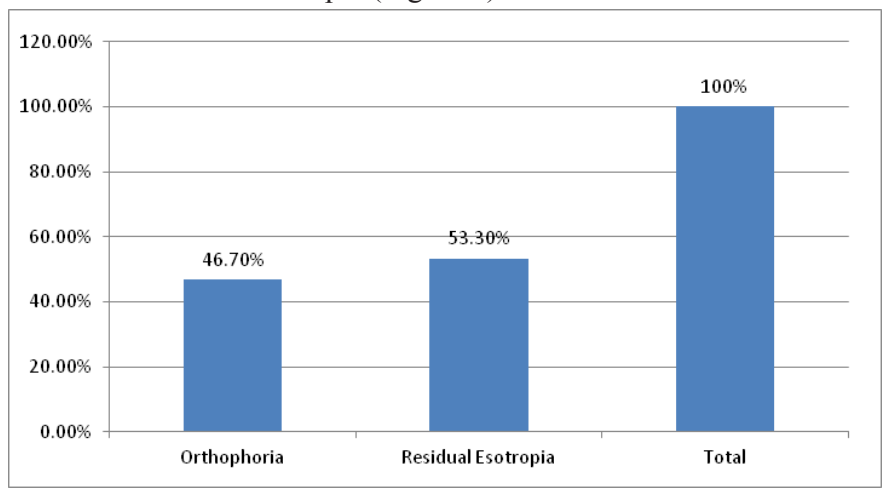

Figure I Chart of Orthophoria and Residual esotropia.

\section{Angle of deviation}

The initial uncorrected deviation at near was $19.1 \pm 6.4$ in good stereopsis group and was $25.45 \pm 10.31$ in poor stereopsis group (P value 0.08 ). The initial uncorrected deviation at distant was $19.40 \pm 8.42$ in good stereopsis group and was $21.55 \pm 8.98$ in poor stereopsis group ( $\mathrm{P}$ value 0.53 ). The final angle of deviation after treatment at distant was $0.86 \pm 0.76$ in good stereopsis group and was $2.2 \pm 0.49$ in poor stereopsis group (P value 0.03). The mean of final deviation after treatment at near was $1.30 \pm 0.43$ in good stereopsis group and was $2.56 \pm 1.29$ in poor stereopsis group (P value 0.006 ) (Table 3 ).

\section{Fusional ability}

The mean distant fusional ability at final visit was $1.90+0.96$ and at near was $1.87+0.93$. There were $50 \%(n=15)$ patient were with distant fusional ability, $10 \%(\mathrm{n}=3)$ patients were diplopic and $40 \%$ $(\mathrm{n}=12)$ patients were with suppression at final visit. There were $50 \%$ $(\mathrm{n}=15)$ patients were with near fusional ability. $13.3 \%(\mathrm{n}=4)$ patients with diplopia and $40 \%(n=12)$ patients were with suppression. The distantfusional ability were present at final visit in 10 patients in good stereopsis group, and 5 patients were with fusion, 3 patients with diplopia and 12 patients were with suppression in poor stereopsis group $\left(\mathrm{p}_{\mathrm{chi}}\right.$ value 0.001$)$.The 10 patients with fusion were present in good stereopsis group at near, 5 patients were with fusion, 4 patients were with diplopia and 11 patients were with suppression in poor stereopsis group at near $\left(\mathrm{P}_{\text {chi }}-\right.$ value 0.001) (Table 4). 
Table 3 Status of stereopsis with general variables and angle of deviation

\begin{tabular}{|c|c|c|c|}
\hline \multirow{2}{*}{ Variables } & \multicolumn{2}{|c|}{ Stereopsis (mean + S.D) } & \multirow{2}{*}{$\begin{array}{l}\text { P- } \\
\text { Value }\end{array}$} \\
\hline & Good & Poor & \\
\hline Age at presumed onset & $2.05+1.49$ & $3.4+1.35$ & 0.19 \\
\hline Age at final visit & $5.20+1.03$ & $6.6+1.60$ & 0.018 \\
\hline Gender & $1.40+0.51$ & $1.45+0.5 \mathrm{I}$ & 0.803 \\
\hline $\begin{array}{l}\text { Initial uncorrected deviation } \\
\text { at distance }\end{array}$ & $0.86+0.76$ & $3.1+2.22$ & 0.53 \\
\hline $\begin{array}{l}\text { Initial uncorrected deviation } \\
\text { at near }\end{array}$ & $19.1+6.4$ & $25.45+\mid 0.31$ & 0.087 \\
\hline $\begin{array}{l}\text { Final deviation after treatment } \\
\text { at distant }\end{array}$ & $19.40+8.42$ & $21.55+8.98$ & 0.003 \\
\hline $\begin{array}{l}\text { Final deviation aftertreatment } \\
\text { at near }\end{array}$ & $1.30+0.34$ & $2.56+1.29$ & 0.006 \\
\hline
\end{tabular}

Table 4 Status of stereopsis with General variables and Fusional ability

\begin{tabular}{|c|c|c|c|}
\hline \multirow{2}{*}{ Variables } & \multicolumn{2}{|c|}{ Stereopsis } & \multirow{2}{*}{ P-value } \\
\hline & Good & Poor & \\
\hline $\begin{array}{l}\text { Age at presumed onset } \\
(\text { mean+S.D) }\end{array}$ & $2.05+1.49$ & $3.40+1.35$ & 0.16 \\
\hline Age at final visit (mean+S.D) & $5.20+1.03$ & $6.60+1.60$ & 0.15 \\
\hline \multicolumn{4}{|l|}{ Gender\%(n) } \\
\hline Male & 6 & II & 0.79 \\
\hline Female & 4 & 9 & \\
\hline \multicolumn{4}{|l|}{ Near Fusional Ability \%(n) } \\
\hline Fusion & 10 & 5 & 0.001 \\
\hline Diplopia & 0 & 4 & \\
\hline Suppression & 0 & II & \\
\hline \multicolumn{4}{|l|}{ Distant fusional ability \%(n) } \\
\hline Fusion & 10 & 5 & 0.001 \\
\hline Diplopia & 0 & 3 & \\
\hline Suppression & 0 & 12 & \\
\hline
\end{tabular}

\section{Association with age and gender}

The chi-square test show no association ( $p$ - value 0.16 ) of presume onset of age, Age at final visit (P-value 0.15 ) and gender (p- value o.555) with final stereopsis.

\section{Discussion}

In this study, despite using full correction and having well centered eyes, only $33 \%$ of total patients had 100 arcsec or better stereoacuity, the mean refractiveerror and final corrected angle of deviation were smaller in group of good stereopsis. This study also reveals that orthotropic group had better stereopsis then residual group. Leske and collegues ${ }^{7}$ also showed that maximum angle of horizontal strabismus is related to true stereopsis. They reported that stereopsis may seems to be rare with a horizontal deviation of $>4$ degree, there was no patient found who had true stereopsis with horizontal deviation of $>10$ degree of deviation, $12 \%$ of their patients had accommodative esotropia.

It is showed by most of the studies that stereopsis has onset at the age of 3-4months and 4-12 months,stereo acuity maturation rate is higher. ${ }^{8-9}$ Presentation of accommodative esotropia is mostly between 2 to 3 years of age. So, if refractive accommodative esotropic patients are orthophoric after full correction, then they have the chances to have good stereo acuity. However, Birch ${ }^{10}$ noted the functional organization of the maturing visual system shows to be sensitive to disturbing the abnormal visual experiences during the first month of life, and expectedly continues till 4 years of age. It is also noted that even full orthophoria is achieved, the abnormal ocular experience act as a factor for the unfavorable prognosis of normal development of stereopsis.

In this study, there was no difference in age between the poor and good stereopsis group. Even if parents' recalling of the occurrence of esodeviation is wrong, there are differences in the age of stereopsis and other factors that affect the stereopsis. Moreover, there were previous reports that the binocular sensory outcome may be effected by duration of eye misalignment of both eyes. ${ }^{1,4}$ In our study, even with no drastic difference in duration of esodeviation in two groups as both groups had almost difference of one year in onset of esotropia and start wearing the glasses. So this may affect negatively on recovery of stereopsis. Early detection and treatment are important for maintaining good stereopsis.

\section{Strength and limitations of study}

a. The main limitation of the study was small sample size.

b. As titmus fly test is used for stereopsis, so it is prone to the monocular clues.

\section{Acknowledgments}

None.

\section{Competing interest}

The authors declare that they have no competing interests.

\section{Funding statement}

This research received no specific grant from any funding agency in the public, commercial or not-for-profit sectors.

\section{References}

1. Wilson ME, Bluestein EC, Parks MM. Binocularly in accommodative esotropia. J Pedriatr Ophthalmol Strabismus. 1993;30(4):233-236.

2. Swan JC. Accommodative esotropia long range follow up. Ophthalmology. 1983;90(10):1141-1145.

3. MulvihillA, MacCann A, Flitcroft $J$, et al. Outcome in refractive accommodativeesotropia. Br J Ophthalmol. 2000;84(7):746-749.

4. Fawcett S, Leffler J, Birch EE. Factors influencing stereoacuity inaccommodative esotropia. J AAPOS. 2000;4(1):15-20.

5. Matsuo T, Yamane T, Fujiwara H, et al. Predictive factors for long-term outcome of stereoacuity in Japanesepatients with pure accommodative esotropia. Strabismus. 2005;13(2):79-84.

6. Fawcett SL, Birch EE. Risk factors for abnormal binocular vision aftersuccessful alignment of accommodative esotropia. $J$ AAPOS. $2003 ; 7(4): 256-262$.

7. Leske DA, Holmes JM. Maximum angle of horizontal strabismusconsistent with true stereopsis. J AAPOS. 2004;8(1):28-34. 
8. Birch EE, Morale SE, Jaffrey BG, et al. Measurment of tereoacuity outcomes at age 1 to 24 months: RandotStereocards. J AAPOS. 2005;9(1):31-36.

9. Birch EE, Gwaizada J, Held R. Stereoacuity development for crossed and crossed disparities in human infants. Vision Res. 1982;22(5):507-513.
10. Birch EE, Maeshall Parks. Binocular sensory outcomes in accomodative ET. J AAPOS. 2003;7(6):369-373 